\title{
Perceived Accessibility as a Predictor of Youth Smoking
}

\author{
Chyke A. Doubeni, MD, MPH', \\ Wenjun $L i, P b D^{2}$ \\ Hassan Fouayzi, MS ${ }^{3}$ \\ Josepb R. DiFranza, $M D^{1}$ \\ 'Department of Family Medicine and \\ Community Health, University of Massa- \\ chusetts Medical School, Worcester \\ ${ }^{2}$ Division of Preventive and Behavioral \\ Medicine, Department of Medicine, \\ University of Massachusetts Medical \\ School, Worcester \\ ${ }^{3}$ Meyers Primary Care Institute, University \\ Massachusetts Medical School, Worcester
}

Conflicts of interest: none reported

\section{CORRESPONDING AUTHOR}

Chyke Doubeni, MD, MPH

Department of Family Medicine and

Community Health

University of Massachusetts Medical School 55 Lake Ave North

Worcester, MA 01655

chyke.doubeni@umassmed.edu

\begin{abstract}
PURPOSE Youths who smoke are more likely to perceive that cigarettes are easily accessible, but the relationship between perceived accessibility of cigarettes and the risk of smoking is not clear. The objective of this study was to determine whether perceived accessibility predicted future smoking among youths.
\end{abstract}

METHODS This study used data from the second Development and Assessment of Nicotine Dependence in Youth (DANDY-2) study, a 4-year (2002-2006) cohort study that began with 1,246 sixth-grade students in 6 Massachusetts communities. DANDY-2 comprised 11 waves of in-person interviews. A total of 1,195 students who were aged 11 to 14 years at the baseline interview in 2002 were eligible for inclusion in this report. The outcomes for this study were the onset of smoking initiation and regular tobacco use.

RESULTS At baseline 1,027 students had never smoked cigarettes, and 168 had previously initiated smoking. During the 4 years of the study, 177 students newly initiated smoking, and 109 became regular smokers. In unadjusted citystratified Cox proportional hazard models, perceived accessibility increased the risk for smoking initiation among nonsmokers and regular smoking among all participants in a dose-response fashion. Perceived accessibility also increased the risk for smoking progression among initiators in a dose-response fashion. The associations between perceived accessibility and smoking were robust to adjustment for peer and parental smoking. Youths with both perceived accessibility and peer-smokers had a higher risk of regular smoking and progression after initiation than either factor alone. These associations were stable to adjustment for potential confounders other than peer smoking.

CONCLUSIONS Perceived accessibility increases the risk for smoking among youths and has a stronger effect among those with peer smokers. There may be a role for identifying this group of youths for targeted interventions in child health care settings. Perceived accessibility should be carefully considered and measured in smoking intervention programs for teens.

Ann Fam Med 2008:6;323-330. DOI: 10.1370/afm.841.

\section{INTRODUCTION}

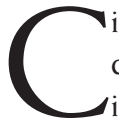

igarette smoking is a major public health challenge worldwide. In developed countries many adult smokers initiated tobacco use durgression to regular tobacco use in adolescence represent potentially preventable milestones that may lead to nicotine addiction ${ }^{1,2}$ and preventable major adverse health consequences. Although several factors have been shown to increase the risk of smoking in adolescence, ${ }_{1}^{3-7}$ the relationship between perceived accessibility and youth tobacco use is poorly understood.

In the United States, a combination of excise taxation, litigation against tobacco companies, and enforcement of laws prohibiting the sale of tobacco products to minors have increased the cost of and the difficulty in obtaining tobacco products. ${ }^{8-14}$ Despite these measures, many youths initiate tobacco use every day. ${ }^{15-17}$ Youths may obtain tobacco products from commercial 
sources ${ }^{17,18}$ or from friends or adult relatives. ${ }^{19,20}$ These potential sources of cigarettes may cause youths, particularly smokers, to believe that tobacco products are easily accessible. ${ }^{20-23}$ It remains unclear, however, whether perceived accessibility is a risk factor for smoking initiation among nonsmoking teens and for the escalation of tobacco use following initiation.

It has been shown that youths who perceive easy access to an illegal substance are more likely to acquire and experiment with it. ${ }^{24}$ Although previous studies have found that perceived accessibility is associated with tobacco use among youths, ${ }^{23,25}$ those studies were limited to cross-sectional analyses. Because youths who smoke may be more likely to perceive easy access to cigarettes, ${ }^{26}$ it is not clear from existing studies whether perceived accessibility predicts future smoking. Additionally, existing literature suggests that peer smoking and perceived accessibility may act jointly to influence youth smoking, but this relationship has not been examined. ${ }^{26}$ The objective of this study was to determine whether youths' perception of the accessibility of cigarettes predicts future patterns of smoking.

\section{METHODS}

\section{Design, Setting, and Participants}

The data for this study were derived from the second Development and Assessment of Nicotine Dependence in Youth (DANDY-2) study. The details of the DANDY-2 study, including methods for standardization of the interviews, have been fully described previously. ${ }^{27,28}$ In summary, DANDY-2 is a prospective cohort study of English-speaking students attending schools in 6 central Massachusetts communities.

The DANDY-2 study started with a racially diverse nonprobability sample of 1,246 sixth-grade students who were observed for 4 years from January 2002 to February 2006. ${ }^{27,28}$ We excluded 38 students who participated in the first interview only. This report is restricted to the 1,195 students who had never before puffed on a cigarette or smoked less than once a week at the time of the baseline interview. The study was approved by the institutional review board of the University of Massachusetts Medical School.

\section{Data Collection}

The DANDY-2 study comprised up to 11 waves of standardized confidential face-to-face interviews conducted in school at a frequency of up to 3 per school year by 3 trained interviewers. Interviews were conducted with the aid of personal landmarks, bounded recall, decomposition, and a personalized calendar, techniques that have been shown to facilitate accurate recall of dates and events. ${ }^{29}$ A calendar of important events was created for each tobacco user to serve as a memory aid and to assist in establishing the timing and sequencing of smoking events at each interview.

\section{Outcome Measures}

The study outcomes were the onset of smoking initiation and regular tobacco use among the cohort. Smoking initiation was defined as puffing on a cigarette for the first time during the period under study. Regular smoking was defined as the onset of weekly smoking (or smoking at least once every week) during the period under study. This outcome was determined in 2 ways. Because we were interested in finding out whether perceived accessibility predicted the onset of future regular smoking among the cohort, we determined the onset of regular smoking among all students included in this report $(n=1,195)$. We also defined an outcome of smoking progression among initiators, defined as escalation to regular smoking subsequent to the smoking debut $(n=345)$.

Data on smoking initiation and the frequency of tobacco use were collected during each of the 11 interviews. Specific dates were recorded when available for the first puff on a cigarette and for the first date of weekly smoking. Otherwise, if an event was recalled to have occurred at the beginning of the month, it was recorded as the 7 th of the month, the middle as the 15 th, and the end of the month as the 25 th.

\section{Predictor}

The perception that cigarettes were easy to obtain (perceived accessibility) was assessed with the item: "Do you agree or disagree with the following statement: It would be easy for me to get a cigarette." Responses were scored on a 5-point Likert scale ("strongly disagree" to "strongly agree"). Perceived accessibility was assessed at baseline and at yearly intervals thereafter.

\section{Covariates}

We evaluated as candidate covariates several demographic, socioenvironmental, attitudinal, belief, and psychological factors known to be associated with tobacco use. Data on date of birth, sex, participants perceptions about their own weight, number of siblings, and race-ethnicity were obtained at baseline. Race-ethnicity was based on self-report and was categorized as Hispanic, non-Hispanic white, or other.

We collected data on the number of friends that smoked (peer smoking), the presence of adult smokers in the home, and parental smoking. ${ }^{28}$ Participants were also asked about how their parents (perceived parental approval of smoking) or friends (perceived peer approval of smoking) would react if they smoked, and about parental approval of watching R-rated mov- 
ies (categorized as "yes" vs "no"). They were also asked whether they had a favorite tobacco advertisement and could identify the Joe Camel cartoon character. ${ }^{28}$ Another item asked each participant about the number of stores they knew that will sell cigarettes to minors (knowledge of commercial sources, coded as "none" vs "1 or more stores").

Data were also collected for the following factors that were assessed using items validated in previous studies: psychological factors including coping styles (anger, positive, negative, and avoidant coping) ${ }^{30}{ }_{i}$ self-esteem, ${ }^{31}$ perceived control, ${ }^{31}$ novelty-seeking personality ${ }^{30}$; distractibility, ${ }^{32}$ depression, ${ }^{33}$ and manifest anxiety ${ }^{34}$; being bored in the past 2 weeks ${ }^{28}$; school disaffection ${ }^{35}$; academic achievement ${ }^{28}{ }_{i}$ bonding with parents ${ }^{35}$; getting along with parents ${ }^{28}$; parental involvement in the child's life ${ }^{35}$; participants' beliefs that smoking makes a person popular, look cool, or fit in with other youths ${ }^{28}$; and religiosity, ${ }^{36}$ participation in Boy Scouts, Girl Scouts, extracurricular activities, lessons, and sports. ${ }^{28}$ The internal consistency of the multi-item scales in the DANDY-2 study has been described previously. ${ }^{28}$ We also had data on the number of computers in the home and highest level of parental education.

\section{Data Analysis}

SAS software, version 9.1 (SAS Institute, Inc, Cary, North Carolina), was used for analyses. The last observation was carried forward for students with missing covariate data who participated in a subsequent interview during the study. Kaplan-Meier analyses were used to determine the probability of smoking initiation among baseline nonsmokers, regular smoking among all participants, and smoking progression among initiators.

We used Cox proportional hazards models to determine whether perceived accessibility increased the risk for smoking initiation among baseline nonsmokers $(n=1,027)$, regular smoking among all participants $(\mathrm{n}=1,195)$ and smoking progression among initiators $(\mathrm{n}=345),{ }^{37}$ and we used city-stratified Cox models to account for clustering of participants in their city of residence. We did not account for clustering within schools in the analyses, because many participants changed schools frequently during the period under study, and this information was not tracked. The time to smoking initiation or regular use was defined from the date of the baseline interview. For the outcome of smoking progression among initiators, we used the date of the first puff on a cigarette as time zero. For participants who had initiated smoking prior to the baseline interview ( $\mathrm{n}=168$ ), we used the date of the baseline interview as time zero in determining accrued person- time. For all outcomes examined, the time-to-event was censored at the date of the last completed interview. Because some of the participants had initiated smoking prior to the baseline interview, analyses on smoking initiation were restricted to participants who had not previously puffed on a cigarette at the date of the baseline interview. Analyses on smoking progression among initiators were restricted to those who had initiated smoking either before or during the follow-up period. To account for repeated measures within study participants during the period under study, indicator variables for the predictors and covariates were entered as timevarying factors in the models.

A series of Cox models examined the impact of having potential social sources of cigarettes (peer or parental smoking) on the relationship between perceived accessibility and smoking initiation, regular tobacco use, or smoking progression among initiators. The magnitude of the regression coefficient for perceived accessibility in the unadjusted analyses was compared with that from each model, adjusted separately for peer or parental smoking, to determine whether peer or parental smoking mediated the relationship between perceived accessibility and smoking rates. ${ }^{38}$ In single-predictor Cox models, there was no association between knowledge of commercial sources and smoking rates; therefore, this factor was not assessed in the mediation analyses.

We assessed interaction between perceived accessibility and potential social or commercial sources of cigarettes $^{39}$ and found a significant interaction effect between perceived accessibility and peer smoking. We therefore used indicator variables for combinations of the 2 factors in the final Cox models for analyses on all outcomes. We also determined the synergism between peer smoking and perceived accessibility, that is, the degree to which peer smoking enhances the effects of perceived accessibility on smoking rates, as has been previously described by Hallqvist et al ${ }^{40}$ and Andersson et al. ${ }^{41}$

We used the variance inflation factor and correlation coefficient to assess for collinearity or multicollinearity in the multivariable models. ${ }^{42}$ After consideration of multicollinearity, we retained the following covariates for potential inclusion in the multivariable models: age; sex; race-ethnicity; number of siblings; knowledge of product affiliation of the Joe Camel character; having a favorite cigarette advertisement; parental permissiveness of watching R-rated movies; parental smoking; perceived parental or peer approval of smoking; belief that smoking makes a person popular, look cool, or fit in; involvement in community activities or Boy or Girl Scouts; impulsivity; concerns about weight; anger coping 
positive self-esteem; positive coping; depression; academic performance; school disaffection $_{i}$ boredom; $_{i}$ perceived control parental involvement; relationship with mother ${ }_{i}$ being close to mother or father; religiosity; and feeling relaxed the first time inhaling from a cigarette. We selected variables for parsimonious multivariable models for each smoking outcome using stepwise variable selection techniques; variables were entered at a $P=.25$ and retained at $P=.06$. The final models for each outcome were adjusted for age, sex, parental smoking, perceived parental approval of smoking, and anger coping. Models on smoking initiation were also adjusted for participant's concerns about weight, parental permissiveness of watching R-rated movies, and school disaffection. Models on regular smoking and smoking progression among initiators were also adjusted for having a favorite cigarette advertisement, parental involvement, and impulsivity.

\section{RESULTS}

Of the 1,195 participants included in the analyses, 1,027 had never previously smoked at baseline, and 168 had initiated smoking prior to the baseline interview. The baseline demographic characteristics of the participants were as follows: average age 12.1 years (range 11.2-13.7 years); female 52\%; non-Hispanic white $73 \%$, and Hispanic $18 \%$. For parental education, highest educational attainment less than higher school was $5 \%$, high school graduate $20 \%$, some college but did not graduate $16 \%$, college graduate or higher $51 \%$, and unknown $8 \%$. For current parental smoking status, both were nonsmokers 57\%, 1 parent smoked 27\%, both parents smoked $16 \%$.

At baseline, 21\% of the participating students perceived easy accessibility of cigarettes, and $9 \%$ had friends who smoked. These percentages increased with time: in the fourth year of the study period, 50\% perceived easy accessibility of cigarettes and 32\% had smoking friends. By the end of the third study year, $24 \%$ knew of at least 1 store that would sell cigarettes to youths, which increased to $32 \%$ by the end of the fourth year.

\section{Relationship Between Perceived Accessibility and Smoking Experimentation and Escalation}

The cohort contributed a total of 39,893 personmonths of observation time for smoking initiation, 46,932 person-months for regular smoking among all participants, and 8,061 person-months for smoking progression among initiators. The initiation of smoking was observed in 177 subjects, and 109 subjects progressed to regular tobacco use.

The cumulative incidences of the smoking outcomes examined during the 4-year study period are shown in Table 1. In Kaplan-Meier analyses, most participants who progressed to regular smoking after initiation did so within 2 years. There was no apparent plateau in the onset of smoking initiation or progression during the period under study (data not shown).

In unadjusted Cox proportional models, perceived accessibility increased the risk for smoking initiation and regular smoking in a dose-response fashion (Table 2). In further Cox proportional hazards modeling, we dichotomized the indicator for perceived accessibility to ease interpretation of the findings ("strongly agree" and "agree a little" were coded as "yes" [1] and other responses as "no" [0]). In unadjusted analyses, participants who perceived that cigarettes were easy to obtain had an increased risk for smoking initiation compared with those who did not (Table 3). These estimates were 
stable to adjustment for parental smoking, peer smoking, or both. Perceived accessibility also increased the risk for regular smoking; this estimate was also robust to adjustment for parental smoking, peer smoking, or both. The perception that cigarettes were easy to obtain also increased the risk for smoking progression among initiators. This relationship was stable to adjustment for parental or peer smoking, however, because of the small sample sizes in the analyses for this outcome, the estimate for perceived accessibility was no longer statistically significant after adjustment for peer smoking.

\section{Interaction Between Perceived Accessibility and Peer Smoking}

Because we found significant interaction effects between perceived accessibility and peer smoking, we used indicator variables for the interaction between perceived accessibility and peer smoking (coded as 0 vs 1 or more smoking friends) in the final series of Cox models. In unadjusted Cox proportional hazards analyses, the strength of the association with smoking initiation or regular smoking increased in a dose-response fashion from perceived accessibility only through peer smoking to the combined effects of perceived accessibility and peer smoking (Table 4). Because of small sample sizes, however, the association between perceived accessibility alone and smoking progression among initiators was not statistically significant.

The findings on the relationship between smoking outcomes and the combined effect of perceived accessibility with peer smoking were robust to adjustment for the selected covariates (Table 4). The addition of knowledge of commercial sources to the multivariable models (restricted to the last 2 years of the study) did not change the findings. Because feeling relaxed after smoking is a strong predictor of the development of nicotine addiction, ${ }^{27}$ we performed additional multivariable analyses on smoking progression among initiators that included this variable. The findings were unchanged for perceived accessibility only (adjusted hazard ratio $[\mathrm{AHR}]=0.63 ; 95 \%$ confidence interval $[\mathrm{CI}], 0.28-1.43)_{\text {; }}$ peer smoking only $(\mathrm{AHR}=2.25 ; 95 \%$ CI, 1.10-4.60), and both perceived accessibility and peer smoking $(\mathrm{AHR}=3.13 ; 95 \% \mathrm{CI}, 1.68-5.83)$.

We did not find a significant synergism between perceived accessibility and peer smoking on smoking initiation (unadjusted

Table 4. Relationship Between Perceived Accessibility, Peer Smoking, and Smoking Outcomes

\begin{tabular}{|c|c|c|c|c|c|c|}
\hline \multirow[b]{3}{*}{ Characteristics } & \multicolumn{6}{|c|}{ Smoking Outcome, Hazard Ratio $(95 \% \mathrm{Cl})^{a}$} \\
\hline & \multicolumn{2}{|c|}{ Initiation } & \multicolumn{2}{|c|}{ Regular Smoking } & \multicolumn{2}{|c|}{ Progression Among Initiators } \\
\hline & Unadjusted & Adjusted $^{b}$ & Unadjusted & Adjustedc & Unadjusted & Adjusted ${ }^{\mathrm{c}}$ \\
\hline $\begin{array}{l}\text { Neither perceived accessibility } \\
\text { nor peer smoking }\end{array}$ & ref & ref & ref & ref & ref & ref \\
\hline $\begin{array}{l}\text { Has perceived accessibility } \\
\text { but no peer smokers }\end{array}$ & $\begin{array}{c}2.00 \\
(1.31-3.06)\end{array}$ & $\begin{array}{c}1.53 \\
(0.98-2.41)\end{array}$ & $\begin{array}{c}2.32 \\
(1.07-5.02)\end{array}$ & $\begin{array}{c}1.16 \\
(0.49-2.75)\end{array}$ & $\begin{array}{c}0.83 \\
(0.39-1.75)\end{array}$ & $\begin{array}{c}0.64 \\
(0.28-1.44)\end{array}$ \\
\hline $\begin{array}{l}\text { Peer smoking but no perceived } \\
\text { accessibility }\end{array}$ & $\begin{array}{c}5.60 \\
(3.76-8.36)\end{array}$ & $\begin{array}{c}4.04 \\
(2.66-6.15)\end{array}$ & $\begin{array}{c}9.53 \\
(4.92-18.47)\end{array}$ & $\begin{array}{c}4.85 \\
(2.35-10.02)\end{array}$ & $\begin{array}{c}2.98 \\
(1.55-5.75)\end{array}$ & $\begin{array}{c}2.24 \\
(1.09-4.62)\end{array}$ \\
\hline $\begin{array}{l}\text { Both perceived accessibility } \\
\text { and peer smokers }\end{array}$ & $\begin{array}{c}6.82 \\
(4.53-10.29)\end{array}$ & $\begin{array}{c}3.65 \\
(2.26-5.9)\end{array}$ & $\begin{array}{c}27.63 \\
(15.61-48.91)\end{array}$ & $\begin{array}{c}8.27 \\
(4.23-16.19)\end{array}$ & $\begin{array}{c}4.74 \\
(2.69-8.35)\end{array}$ & $\begin{array}{c}3.08 \\
(1.64-5.78)\end{array}$ \\
\hline \multicolumn{7}{|c|}{$\begin{array}{l}\text { a All estimates shown were derived from city-stratified Cox proportional hazards model to account for clustering within students' city of residence. } \\
\text { b Model was adjusted for age, sex, parental smoking, perceived parental approval of smoking, concerns about weight, anger coping, parental permissiveness } \\
\text { of watching R-rated movies, and school disaffection. } \\
\text { ' Model was adjusted for age, sex, parental smoking, perceived parental approval of smoking, having a favorite cigarette advertisement, parental involvement, } \\
\text { anger coping, and impulsivity. }\end{array}$} \\
\hline
\end{tabular}


synergy index $[\mathrm{SI}]=1.04 ; 95 \% \mathrm{CI}, 0.63-1.73)$; however, there was significant synergism between the 2 factors for regular smoking for both unadjusted $(\mathrm{SI}=2.70 ; 95 \%$ CI, 1.63-4.50) and adjusted (SI $=1.96 ; 95 \% \mathrm{CI}, 1.03$ 3.72 ) analyses. The adjusted attributable proportion that was due to the interaction, that is, the proportion of regular smoking among those with smoking friends who perceived easy access to cigarettes that was due to the combined effect of these 2 factors, was $44.2 \%$ (95\% CI, 14.5\%-73.8\%). The findings were similar for the outcome of smoking progression among initiators for unadjusted $(\mathrm{SI}=2.07 ; 95 \% \mathrm{CI}, 0.83-5.14)$ and adjusted $(\mathrm{SI}=2.13 ; 95 \% \mathrm{CI}, 0.53-8.51)$ analyses, but the estimates were less stable because of smaller sample sizes. The adjusted attributable proportion for smoking progression among initiators was $37.2 \%$ (95\% CI, $-5.8 \%$ to $80.3 \%)$.

\section{DISCUSSION}

In this prospective study, the perception that cigarettes were easy to obtain increased the risk for smoking initiation and regular tobacco use. Our findings from this study show that neither peer smoking nor parental smoking mediate the relationship between perceived accessibility and smoking initiation or progression. Rather, the combination of perceived accessibility and peer smoking had a stronger effect on youth smoking than either factor alone.

In cross-sectional analyses among seventh-grade students, Robinson et al reported that those perceiving easy access to cigarettes had 2.13 greater odds of experimenting with smoking than those who did not. ${ }^{25}$ In a similar study among 10th-grade students in California, Unger et al found 1.3 greater odds of current smoking among those perceiving easy access of tobacco products. ${ }^{23}$ Youths who have already smoked may perceive cigarettes to be more accessible; consequently, those studies were unable to determine the direction of the relationship between perceived accessibility and tobacco use. Because our data were collected prospectively, we were able to show the direction of this association: in youths who had never before smoked cigarettes, perceived accessibility predicted future smoking. In addition, the observation of a strong doseresponse relationship between perceived accessibility and tobacco use supports the conclusion that perceived accessibility contributes to youth smoking.

Surprisingly, we found that youths who perceived easy access and had friends who smoked were more likely to smoke regularly than those exposed to either factor alone. The 2 factors combined had a synergistic effect with regards to regular tobacco use. In the adjusted analyses on smoking initiation, however, there was no synergism between perceived accessibility and peer smoking, suggesting that perceived accessibility and peer smoking have independent effects on smoking initiation. These findings may be explained by the mechanisms by which perceived accessibility and peer smoking act to promote smoking. Peer smoking is an established risk factor for youth smoking ${ }^{5}$ and, as expected, we found that peer smoking increased the risk for future smoking independent of all other factors examined. Adolescents who smoke regularly typically purchase their tobacco from stores and then share their cigarettes with their peers, becoming the primary source for new smokers. ${ }^{43}$ Youths also learn about commercial sources of cigarettes from their peers. ${ }^{19,44}$ Thus, smoking peers contribute to perceptions about accessibility of cigarettes. ${ }^{44,45}$ Based on our findings, perceived accessibility contributes to the escalation of tobacco use both independently and through its interaction with peer smoking. Thus, the effects of perceived accessibility and peer smoking are intertwined; greater availability increases smoking rates, and a higher prevalence of smoking among youths increases perceived accessibility through peers that smoke. ${ }^{26}$

\section{Strengths and Weaknesses}

The data for this study were collected prospectively with multiple rounds of interviews over a 4-year period, reducing the potential for recall bias and allowing us to determine the onset of smoking and to establish the temporal relationship between perceived accessibility and cigarette smoking. Limitations of this study include the reliance on self-reported tobacco use, although previous studies support the accuracy of selfreported tobacco use. ${ }^{46,47}$ Youths are more likely to underreport tobacco use, which would likely bias the results towards the null. The sample size for analyses on smoking progression among initiators was small. As a result, our findings on this outcome should be interpreted with caution; the point estimates for the association between perceived accessibility and smoking progression among initiators should not be interpreted as showing a protective effect of perceived accessibility.

\section{Implications for Policy and Practice}

Although restricting youths' access to tobacco products is an effective public health measure, additional interventions may be needed to achieve further decreases in smoking experimentation among youths. ${ }^{48}$ Screening for risk factors for initiation and escalation in clinical and public health settings has the potential for identifying youths at high-risk for tobacco use. Our results show that perceived accessibility is an important contributor to initiation and escalation of smoking among teenagers, and it should be considered and carefully 
measured in future intervention studies. These findings suggest that youths who have peer smokers and perceive easy access may be at high risk for higher levels of smoking and may warrant greater attention in clinical and public health settings. Family physicians and pediatricians currently screen for risk behavior, including peer influences and tobacco use, as part of the Early and Periodic Screening, Diagnosis and Treatment program. ${ }^{49}$ We recommend that clinicians routinely ask youths about their perceptions of the accessibility of tobacco and exposure to peer smokers. Additional studies should examine the feasibility of identifying youth susceptibility to smoking at the time of a health care visit based on a combination of factors, including having peer smokers and perceived accessibility. In addition, future larger studies may be needed to further clarify the relationship between perceived accessibility, peer smoking, and escalation of tobacco use among experimenting youths.

In conclusion, in this study we found a complex relationship between perceived accessibility and smoking among youths. The perception among adolescents that tobacco products are easy to obtain is a risk factor for smoking initiation and progression. Having smoking peers increased the impact of perceived accessibility on smoking among youths even when adjusted for other factors. Studies of tailored interventions targeted at youths who perceive easy access to cigarettes may be useful.

To read or post commentaries in response to this article, see it online at http://www.annfammed.org/cgi/content/full/6/4/323.

Key words: Smoking; tobacco use disorder; adolescent; friends; perception; accessibility

Submitted October 1, 2007; submitted revised December 23, 2007; accepted January 4, 2008.

Funding support: This study was supported by grant 57704 from the Robert Wood Johnson Foundation's Substance Abuse Policy Research Program.

Disclaimer: The funding organization played no role in the design, conduct, analyses, and interpretation of the study and approval of the manuscript.

\section{References}

1. DiFranza JR, Savageau JA, Rigotti NA, et al. Development of symptoms of tobacco dependence in youths: 30 month follow up data from the DANDY study. Tob Control. 2002;11(3):228-235.

2. Gervais A, O'Loughlin J, Meshefedjian G, Bancej C, Tremblay M. Milestones in the natural course of onset of cigarette use among adolescents. CMAJ. 2006;175(3):255-261.

3. Altman DG, Levine DW, Coeytaux R, Slade J, Jaffe R. Tobacco promotion and susceptibility to tobacco use among adolescents aged 12 through 17 years in a nationally representative sample. Am J Public Health. 1996;86(11):1590-1593.
4. Biener L, Siegel MB. The Role of Tobacco Advertising and Promotion in Smoking Initiation. Changing Adolescent Smoking Prevalence: Where It Is and Why. Smoking and Tobacco Control Monograph NO. 34. Bethesda, MD: US Department of Health and Human Services, Public Health Service, National Institutes of Health, National Cancer Institute. NIH Publication No. 92-3316, November; 2001:200-212.

5. Schepis TS, Rao U. Epidemiology and etiology of adolescent smoking. Curr Opin Pediatr. 2005;17(5):607-612.

6. Wellman RJ, Sugarman DB, DiFranza JR, Winickoff JP. The extent to which tobacco marketing and tobacco use in films contribute to children's use of tobacco: a meta-analysis. Arch Pediatr Adolesc Med. 2006;160(12):1285-1296

7. While D, Kelly S, Huang W, Charlton A. Cigarette advertising and onset of smoking in children: questionnaire survey. BMJ. 1996;313(7054):398-399.

8. Lewit EMUS. tobacco taxes: behavioural effects and policy implications. Br J Addict. 1989;84(10):1217-1234.

9. Liang L, Chaloupka F, Nichter M, Clayton R. Prices, policies and youth smoking, May 2001. Addiction. 2003;98(Suppl 1):105-122.

10. Liang L, Chaloupka FJ. Differential effects of cigarette price on youth smoking intensity. Nicotine Tob Res. 2002;4(1):109-114.

11. Sung HY, Hu TW, Ong M, Keeler TE, Sheu ML. A major state tobacco tax increase, the master settlement agreement, and cigarette consumption: the California experience. Am J Public Health. 2005;95(6):1030-1035

12. Tauras JA. Public policy and smoking cessation among young adults in the United States. Health Policy. 2004;68(3):321-332.

13. Tauras JA. Can public policy deter smoking escalation among young adults? J Policy Anal Manage. 2005;24(4):771-784.

14. Thomson CC, Fisher LB, Winickoff JP, et al. State tobacco excise taxes and adolescent smoking behaviors in the United States. J Public Health Manag Pract. 2004;10(6):490-496.

15. Use of cigarettes and other tobacco products among students aged 13-15 years--worldwide, 1999-2005. MMWR Morb Mortal Wkly Rep. 2006;55(20):553-556.

16. Centers for Disease Control and Prevention. DATA2010: the HealthyPeople 2010 database: Centers for Disease Control and Prevention; 2007. http://wonder.cdc.gov/data2010/obj.htm. Accessed Dec 18, 2007.

17. Marshall L, Schooley $M$, Ryan $H$, et al. Youth tobacco surveillance-United States, 2001-2002. MMWR Surveill Summ. 2006;55(3):1-56.

18. Leatherdale ST, Strath JM. Tobacco retailer density surrounding schools and cigarette access behaviors among underage smoking students. Ann Behav Med. 2007;33(1):105-111

19. DiFranza JR, Coleman M. Sources of tobacco for youths in communities with strong enforcement of youth access laws. Tob Control. 2001;10(4):323-328.

20. Forster JL, Klepp K, Jeffery RW. Sources of cigarettes for tenth graders in two Minnesota cities. Health Educ Res. 1989;4:45-50.

21. Cummings KM, Sciandra E, Pechacek TF, Orlandi M, Lynn WR. Where teenagers get their cigarettes: a survey of the purchasing habits of 13-16 year olds in 12 US communities. Tob Control. 1992;1(4):264-267.

22. Forster JL, Wolfson M, Murray DM, Wagenaar AC, Claxton AJ. Perceived and measured availability of tobacco to youths in 14 Minnesota communities: the TPOP Study. Tobacco Policy Options for Prevention. Am J Prev Med. 1997;13(3):167-174.

23. Unger JB, Shakib S, Cruz TB, Hoffman BR, Pitney BH, Rohrbach LA Smoking behavior among urban and rural Native American adolescents in California. Am J Prev Med. 2003;25(3):251-254.

24. Swaim RC. Individual and school level effects of perceived harm, perceived availability, and community size on marijuana use among 12th-grade students: a random effects model. Prev Sci. 2003;4(2):89-98. 
25. Robinson LA, Klesges RC, Zbikowski SM, Glaser R. Predictors of risk for different stages of adolescent smoking in a biracial sample. J Consult Clin Psychol. 1997;65(4):653-662.

26. Turner KM, Gordon J, Young R. Cigarette access and pupil smoking rates: a circular relationship? Health Promot Int. 2004;19(4):428-436.

27. DiFranza JR, Savageau JA, Fletcher K, et al. Symptoms of tobacco dependence after brief intermittent use: the Development and Assessment of Nicotine Dependence in Youth-2 study. Arch Pediatr Adolesc Med. 2007;161(7):704-710.

28. DiFranza JR, Savageau JA, Fletcher K, et al. Susceptibility to nicotine dependence: the Development and Assessment of Nicotine Dependence in Youth 2 study. Pediatrics. 2007;120(4):e974-e983.

29. Bradburn NM, Rips LJ, Shevell SK. Answering autobiographical questions: the impact of memory and inference on surveys. Science. 1987;236(4798):157-161.

30. Wills TA, DuHamel K, Vaccaro D. Activity and mood temperament as predictors of adolescent substance use: test of a self-regulation mediational model. J Pers Soc Psychol. 1995;68(5):901-916.

31. Wills TA. Self-esteem and perceived control in adolescent substance use: comparative tests in concurrent and prospective analyses. Psychol Addict Behav. 1994;8(4):223-234.

32. Wills TA, Cleary S, Filer M, Shinar O, Mariani J, Spera K. Temperament related to early-onset substance use: test of a developmental model. Prev Sci. 2001;2(3):145-163.

33. Kandel DB, Davies M. Epidemiology of depressive mood in adolescents: an empirical study. Arch Gen Psychiatry. 1982;39(10):1205-1212.

34. Reynolds CR, Richmond BO. Revised Children's Manifest Anxiety Scale [RCMAS] Manual. Los Angeles, CA: Western Psychological Services; 1995.

35. Krohn MD, Naughton MJ, Skinner WF, Becker SL, Lauer RM. Social disaffection, friendship patterns and adolescent cigarette use: the Muscatine Study. J Sch Health. 1986;56(4):146-150.

36. Donovan JE, Jessor R, Costa FM. Adolescent health behavior and conventionality-unconventionality: an extension of problem-behavior theory. Health Psychol. 1991;10(1):52-61.

37. Cox DR. Regression models and life tables (with discussion). J Roy Statist Soc Ser B. 1972;34(2):187-220.
38. Baron RM, Kenny DA. The moderator-mediator variable distinction in social psychological research: conceptual, strategic, and statistical considerations. J Pers Soc Psychol. 1986;51(6):1173-1182.

39. Rothman KJ. Epidemiology. An Introduction. New York, NY: Oxford University Press; 2002.

40. Hallqvist J, Ahlbom A, Diderichsen F, Reuterwall C. How to evaluate interaction between causes: a review of practices in cardiovascular epidemiology. J Intern Med. 1996;239(5):377-382.

41. Andersson T, Alfredsson L, Kallberg H, Zdravkovic S, Ahlbom A Calculating measures of biological interaction. Eur J Epidemiol. 2005;20(7):575-579.

42. Tu YK, Kellett M, Clerehugh V, Gilthorpe MS. Problems of correlations between explanatory variables in multiple regression analyses in the dental literature. Br Dent J. 2005;199(7):457-461.

43. Forster J, Chen V, Blaine T, Perry C, Toomey T. Social exchange of cigarettes by youth. Tob Control. 2003;12(2):148-154.

44. Bagott $M$, Jordan C, Wright C, Jarvis S. How easy is it for young people to obtain cigarettes, and do test sales by trading standards have any effect? A survey of two schools in Gateshead. Child Care Health Dev. 1998;24(3):207-216.

45. Killeya-Jones LA, Nakajima R, Costanzo PR. Peer standing and substance use in early-adolescent grade-level networks: a short-term longitudinal study. Prev Sci. 2007;8(1):11-23.

46. Dolcini MM, Adler NE, Lee P, Bauman KE. An assessment of the validity of adolescent self-reported smoking using three biological indicators. Nicotine Tob Res. 2003;5(4):473-483.

47. Patrick DL, Cheadle A, Thompson DC, Diehr P, Koepsell T, Kinne S. The validity of self-reported smoking: a review and meta-analysis. Am J Public Health. 1994;84(7):1086-1093.

48. DiFranza JR. Restricted access to tobacco reduces smoking rates among youth. In: Owing JH, ed. Focus on Smoking and Health Research. Hauppauge, NY: Nova Science; 2005:77-100.

49. Rosenbach ML, Gavin NI. Early and periodic screening, diagnosis, and treatment and managed care. Annu Rev Public Health. 1998; 19:507-525. 